\title{
As linhas fronteiriças dos constituintes da matéria
}

The frontier lines of the constituents of matter

\author{
Diógenes Galetti*1@, Salomon S. Mizrahi² \\ ${ }^{1}$ Universidade Estadual Paulista, Instituto de Física Teórica, São Paulo, SP, Brasil \\ ${ }^{2}$ Universidade Federal de São Carlos, Departamento de Física, CCET, São Carlos, SP, Brasil
}

Recebido em 30 de Maio, 2018. Revisado em 24 de Julho, 2018. Aceito em 29 de Julho, 2018.

\begin{abstract}
Olhando para a carta de nuclídeos como apresentada no endereço web da Agência Internacional de Energia Atômica (IAEA) 1 - que, presume-se, contém todos os nuclídeos conhecidos, naturais e artificiais - constata-se a existência de duas linhas limítrofes, que são as fronteiras dos constituintes da matéria. Admite-se que os átomos mais leves foram formados num processo de nucleossíntese no interior de estrelas enquanto que os mais pesados se formaram na implosão de uma "estrela velha", uma supernova, ou na fusão de duas estrelas de nêutrons. Usando a fórmula semiempírica de massa para os núcleos atômicos, juntamente com a relação de incerteza energia-tempo, mostramos que as linhas limítrofes assim calculadas apresentam uma apreciável concordância quando comparadas com aquelas obtidas dos conjuntos de nuclídeos que se encontram "mais afastados" do vale da estabilidade, ou seja, nas fronteiras dos constituintes da matéria. Também discutimos brevemente, de forma qualitativa, o que se sabe acerca dos processos astrofísicos de nucleogênese dos núcleos pesados e sua relação com as linhas limítrofes. Palavras-chave: carta de nuclídeos, fórmula semiempírica de massa, relação de incerteza energia tempo, linhas limítrofes
\end{abstract}

Looking at the chart of nuclides as presented at the URL of the International Atomic Energy Agency (IAEA) 1] - that, one supposes, contains all the known nuclides, the natural and the artificial ones - one verifies the existence of two delimiting lines admitted to be the borders of the constituents of matter. One assumes that the lighter atoms have been formed in a nucleosynthesis process within the core of certain stars while the heavier were produced during the implosion of old stars, a supernova or in the fusion of two neutron stars. Making use of the nuclear semiempirical mass formula along with the energy-time uncertainty relation of quantum mechanics, we show that the calculated border lines show an appreciable agreement with the data obtained from the Chart of Nuclides, the nuclides that are situated far away from those that define the line, or valley, of stability. We also briefly discuss, qualitatively, what is currently known about the astrophysical nucleogenesis processes of the heavier nuclei and their relation with the border lines.

Keywords: chart of nuclides, semiempirical mass formula, energy-time uncertainty relation, frontier lines

\section{Introdução}

No presente estágio do conhecimento sobre a estrutura da maté ria no Universo ${ }^{1}$, sabe-se (conhecimento sedimentado, de acordo com o entendimento do bioquímico Max Perutz 2] ) que ela é feita de átomos e estes são constituídos de uma "nuvem" de elétrons, de carga elétrica negativa (por convenção), sendo que no seu centro está situado um núcleo constituído de dois tipos de partículas, os prótons (com carga elétrica oposta à carga do elétron, portanto positiva) e os nêutrons, estes são destituídos de carga elétrica. Um átomo neutro é aquele que possui o seu número de elétrons igual ao número de prótons. Um átomo que possui um número de elétrons diferente do número de prótons é dito ser ionizado. O que caracteriza um elemento químico é o número $Z$ de prótons que ele possui em seu núcleo e não o número de elétrons na

\footnotetext{
*Endereço de correspondência: galetti@ift.unesp.br.

${ }^{1}$ Sem entrar na discussão sobre matéria e energia escuras.
}

nuvem, embora as reações químicas envolvam apenas as interações entre as nuvens eletrônicas de átomos e que podem se ligar para formar moléculas. Também, em termos de matéria no sentido latu sensu, devemos incluir as partículas da radiação eletromagnética chamadas fótons, raios-X, raios- $\gamma$; esta denominação decorre do fato de que ela foi estabelecida em diferentes momentos da história. Essencialmente, estas partículas diferem entre si apenas pelas diferentes energias que elas carregam; um fóton na região de micro-ondas carrega menos energia do que um na região da luz visível; este carrega menos energia do que aquele no espectro da radiação ultravioleta. Por sua vez, este carrega menos energia do que um fóton na região do espectro de raios-X e este menos do que um raio- $\gamma$. Contudo, aqui trataremos estritamente dos núcleos atômicos [3].

Um núcleo é caracterizado pelo seu número de massa, $A=Z+N$, onde $N$ é o número de nêutrons que ele contém. A massa de um nêutron é ligeiramente maior 
do que a massa de um próton e, excetuando a carga elétrica que um carrega e o outro não, pró ton e nêutron são chamados genericamente núcleons; assim, um núcleo possui $A$ núcleons. Os átomos com diferentes números de massa $A$ e diferentes números atômicos $Z$ são chamados nuclídeos. Átomos com $Z$ prótons mas com diferentes números de nêutrons são chamados isótopos do elemento químico $X$, que é representado simbolicamente como ${ }_{Z}^{A} X$ ou de forma mais explícita como ${ }_{Z}^{A} X_{N}$. Por exemplo, alguns isótopos do elemento carbono, $C$, são ${ }_{6}^{12} C,{ }_{6}^{13} C$, ${ }_{6}^{14} C$.

Os nuclídeos podem ser classificados em duas categorias: os está veis e aqueles que se transformam, ou radioativos. Um nuclídeo está vel ${ }_{Z}^{A} X$ não se transforma naturalmente em um outro, ele mantém sua identidade ad infinitum, enquanto não interagir com outros. Já um núcleo radioativo se transforma, de forma espontânea, decaindo em outros $\left({ }_{Z}^{A} Y\right.$ ou $\left.{ }_{Z}^{A_{2}} W\right)$ ou fissionando (quebrando-se, na maioria dos casos, em dois outros). Este decaimento ocorre porque a natureza determina que os núcleos devem ter a menor energia possível, assim como também ocorre com os núcleos da categoria dos estáveis que não têm como decair para uma configuração de menor energia. $\mathrm{Na}$ natureza constata-se a existência de pouco mais de 250 nuclídeos estáveis.

Os nuclídeos radioativos se transformam: (1) seja por emissão, de forma espontânea, de partículas de seu núcleo; (2) seja pela absorção de um elétron da nuvem atômica ou; (3) por fissão. Um núcleo pode decair emitindo espontaneamente um ou dois nú cleons ou um núcleo de menor massa; neste último caso o mais comum é a emissão de um núcleo do elemento hélio, ${ }_{2}^{4} \mathrm{He}$ (tamb ém denominado partícula alfa, ou $\alpha$ ). Este processo que é chamado decaimento alfa, ou $\alpha$ tem a sua representação formal escrita como

$$
{ }_{Z}^{A} X \longrightarrow{ }_{Z-2}^{A-4} Y+{ }_{2}^{4} \mathrm{He} .
$$

Nota-se que o número de massa $A$ e o número atômico $Z$ são conservados, antes e depois do decaimento. Diz-se que o número de núcleons e a carga coulombiana são quantidades conservadas seja em um decaimento, numa fissão ou em uma reação nuclear. No decaimento (1) a energia do núcleo ${ }_{Z}^{A} X$ é maior que a soma das energias dos produtos ${ }_{Z-2}^{A-4} Y$ e ${ }_{2}^{4} H e$, ou seja $E\left({ }_{Z}^{A} X\right)>E\left({ }_{Z-2}^{A-4} Y\right)+$ $E\left({ }_{2}^{4} \mathrm{He}\right)$, porém esta diferença de energia não some, ela se transforma. Se inicialmente considerarmos que o núcleo de ${ }_{Z}^{A} X$ é visto em um referencial próprio (estando em um estado de repouso), a diferença de energia transformase em energia cinética dos núcleos que surgem como produto do decaimento, ${ }_{Z-2}^{A-4} Y$ e ${ }_{2}^{4} H e$, que são ejetados numa mesma direção mas em sentidos opostos, devido à lei de conservação do momentum linear. Um outro tipo de decaimento radioativo é o chamado decaimento beta, ou $\beta$; neste caso o nuclídeo ${ }_{Z}^{A} X$ decai transformando-se em outro elemento vizinho na tabela periódica com a emissão: (a) de um elétron $e^{-}$- é o chamado decaimento $\beta^{-}-$; (b) de um pósitron $e^{+}$, o elétron com carga elétrica positiva (a antipartícula do elétron) - é o decaimento $\beta^{+}-$; e (c) por captura de um elétron da nuvem eletrônica, processo conhecido como captura eletrônica (CE). Formalmente estes três processo são escritos como

$$
\begin{array}{rlll}
{ }_{Z}^{A} X & \longrightarrow & { }_{Z+1}^{A} Y+e^{-}+\bar{\nu} \quad\left(\beta^{-}\right) \\
{ }_{Z}^{A} X & \longrightarrow & { }_{Z-1}^{A} W+e^{+}+\nu \quad\left(\beta^{+}\right) \\
{ }_{Z}^{A} X+e^{-} & \longrightarrow & { }_{Z-1}^{A} W+\nu \quad(C E) .
\end{array}
$$

Os processos de transmutação $\beta^{+}$e de $C E$ competem entre si. As partículas $\nu$ e $\bar{\nu}$, que têm massa quase nula e são desprovidas de carga elétrica, são emitidas nos três processos listados; elas são chamadas neutrino e antineutrino, respectivamente. Estas partículas interagem muito fracamente com prótons e nêutrons, porém são essenciais para assegurar leis de conservação, tanto de energia como do momentum linear. A energia do lado esquerdo de cada uma das equações (2) é maior que a energia dos produtos, no lado direito.

Um fato digno de nota diz respeito à vida na Terra e aos elementos que constituem as macromoléculas de RNA e DNA ${ }^{2}$ que são essenciais para a codificação e produção de proteínas nas células, e sobre as quais se sabe que elas são estruturadas como um arranjo bastante singular constituído por cinco elementos leves, o hidrogênio $\left({ }_{1} H\right)$, o carbono $\left({ }_{6} C\right)$, o nitrogênio $\left({ }_{7} N\right)$, o oxigênio $\left({ }_{8} O\right)$ e o fósforo $\left({ }_{15} P\right)$ [4]. Cada um destes elementos possui naturalmente vários isótopos (diferentes números de nêutrons) naturais e que não são radioativos, ou seja, a soma das abundâncias relativas (isotópicas) para cada elemento é $100 \%$, veja a Tabela 1 . Não obstante, isótopos radioativos artificiais destes elementos podem ser produzidos em reatores nucleares. Os átomos que constituem uma molécula de DNA se ligam quimicamente, e isto significa que nada impede que ela contenha todos os diferentes isótopos naturais. Ela é bastante estável contra mutações (há mecanismos biológicos de correção de erros), embora algumas destas possam ser nefastas quando induzidas por radioatividade externa.

${ }^{2}$ Siglas em inglês para ácido ribonucleico e ácido desoxirribonucleico.

Tabela 1: Isótopos estáveis dos elementos químicos que compõem a macromolécula do DNA e as abundâncias relativas, em percentagens. Valores obtidos na URL http://www.periodictable.com/Isotopes/001.1/index.dm.html

\begin{tabular}{cccccccccc}
\hline${ }_{1}^{1} \mathrm{H}$ & ${ }_{1}^{2} \mathrm{H}$ & ${ }_{6}^{12} \mathrm{C}$ & ${ }_{6}^{13} \mathrm{C}$ & ${ }_{7}^{14} \mathrm{~N}$ & ${ }_{7}^{15} \mathrm{~N}$ & ${ }_{8}^{16} \mathrm{O}$ & ${ }_{8}^{17} \mathrm{O}$ & ${ }_{8}^{18} \mathrm{O}$ & ${ }_{15}^{31} \mathrm{P}$ \\
\hline 99,885 & 0,015 & 98,89 & 1,11 & 99,634 & 0,366 & 99,762 & 0,038 & 0,2 & 1,0 \\
\hline
\end{tabular}


Todavia, se pelo menos um desses cinco elementos tivesse um isótopo natural radioativo (i.e. abundância isotópica não nula), ele também seria incorporado ao DNA, na proporção de sua abundância relativa, e neste caso a consequência seria uma molécula de DNA instável. Decaindo por emissão- $\beta$, a estrutura da macromolécula seria destruída ou então ela induziria uma transcrição com erros (ou mesmo sua impossibilidade) para a síntese de proteínas 3 .

Todos os nuclídeos conhecidos, naturais e aqueles produzidos em laboratório, podem ser representados em uma carta, colocando cada nuclídeo em um quadradinho, com eixos cartesianos $Z \times N$, como pode ser visto no endereço web da Agência Internacional de Energia Atômica (IAEA) 11. Na Figura 1 apresentamos parte da carta contendo os nuclídeos estáveis e aqueles cinco elementos básicos que entram na estrutura das macromoléculas referidas. Este assunto foi abordado de forma elegante e clara por G. Marx que discutiu, de forma bastante didática, a física dos nuclídeos e sua relação com a Vida em um artigo intitulado Life in the nuclear valley [5].

Como se formaram os átomos em nosso Universo? As respostas mais plausíveis são aquelas que foram propostas a partir das observações e pesquisas feitas na área de estudo chamada nucleossíntese ou nucleogênese. Na seção 2 faremos uma breve narrativa sobre a síntese de átomos

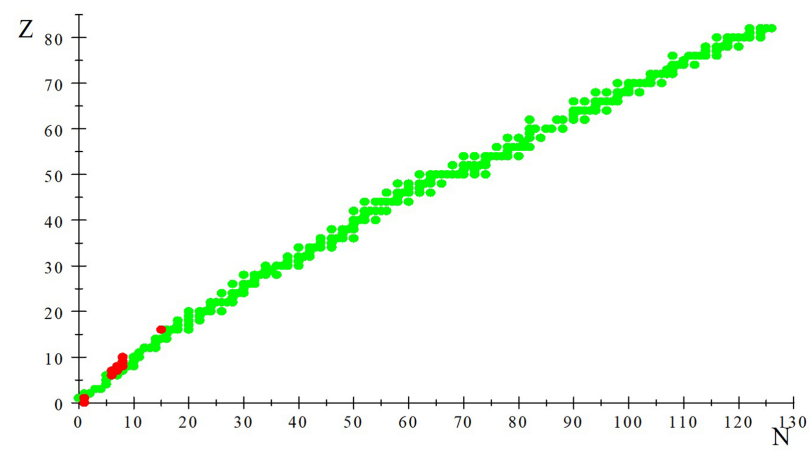

Figura 1: Distribuição de 254 nuclídeos estáveis no plano $Z \times N$. Pontos na cor vermelha (cinza mais escuro para uma imagem em tons de cinza) correspondem aos cinco elementos que compõem as macromoléculas RNA e DNA.

${ }^{3}$ Por exemplo, se o isótopo do hidrogênio, trítio $\left({ }^{3} H\right)$, tivesse na Terra abundância relativa não nula ele estaria presente nas moléculas de RNA e DNA na sua devida proporção. Dado que seu tempo de meia vida - por tempo de meia vida entende-se o tempo necessário para que uma amostra contendo $N_{0}$ nuclídeos radioativos se reduza à metade - é de cerca de doze anos, ele decai transmutando-se em um átomo de hélio, ${ }^{3} \mathrm{He}$, que é estável e tem abundância relativa muito pequena em relação ao outro isótopo, o ${ }^{4} \mathrm{He}, 1: 730.000$. Contudo, devido à sua estrutura eletrônica própria ele não se ligaria quimicamente aos demais átomos da macromolécula, originando portanto uma estrutura molecular diferente, cujo papel não seria mais o mesmo que aquele da molécula de DNA original. Disso, pode-se cogitar - de fato, um truísmo que a Natureza escolheu criteriosamente os elementos químicos mais adequados para construir as macromoléculas fundamentais para sustentar a vida. que ocorre seja no interior de estrelas, seja na colisão e subsequente coalescência de estrelas de nêutrons, assim como na implosão de uma estrela, que ocorre no fim de sua evolução: a estrela velha desaba sobre si mesma devido à força gravitacional. Na seção 3 discutiremos a chamada fórmula semiempírica de massa. Na seção 4 apresentaremos uma explicação simples para a localização das linhas de fronteira observadas na carta de nuclídeos. Estas linhas representam o conjunto daqueles nuclídeos conhecidos, os quais se encontram mais afastados da linha de estabilidade, ou seja são as linhas fronteiriças, ou limitrofes, dos constituintes da matéria.

\section{Nucleossíntese}

Admite-se que os nuclídeos mais leves, até o ferro $\left({ }^{26} \mathrm{Fe}\right)$ [6], se formam no interior das estrelas a partir da fusão nuclear de constituintes mais fundamentais e mais leves. O estudo desses núcleos está na base da compreensão de como os elementos químicos são produzidos na Natureza e de onde provém a energia emanada pelas estrelas. Também admite-se que os núcleons e os elétrons têm sua origem a partir da grande explosão primordial, o Big Bang, e a evolução da abundância relativa dos elementos primordiais pode ser vista na Figura 2. O estudo da nucleossíntese está baseado no paradigma do Big Bang $4^{4}$ cujas etapas principais de evolução são três. A primeira (tempo $t \lesssim 0,01 s$ e temperatura $T \sim 10^{11} K$ ) consiste na explosão e expansão súbita de "nosso Universo" com grande abundância de fótons com relação àquela de núcleons; o modelo estima $10^{9}: 1$. Na segunda delas $(t \lesssim 1 \mathrm{~s}$ e $T \sim 10{ }^{10} \mathrm{~K}$, a temperatura diminui por um fator 10 com relação à etapa anterior) estabelece-se um equilíbrio entre a existência de prótons e nêutrons na razão $6: 1$. Na terceira $\left(t \sim 1\right.$ min e $\left.T \sim 1-3 \times 10{ }^{9} K\right)$ o elemento ${ }^{4} \mathrm{He}$ é produzido e elementos mais pesados também o serão subsequentemente, embora suas abundâncias relativas sejam ainda muito pequenas, como pode ser visto no gráfico na Figura 2 .

Em sequência, o Universo continua se expandindo e a nucleossíntese do Big-Bang cessa quando do início de formação das estrelas e dos aglomerados galácticos. Após a sua formação, as estrelas, por sua vez, começam a produzir novos elementos em seu caroço, onde a pressão é mais alta do que na sua superfície. Lá ocorrem as reações de fusão termonuclear onde são sintetizados elementos, desde os mais leves até os mais pesados, como, por exemplo, o elemento ferro. Porém, esses são produzidos somente nas estrelas de grande massa, bem maiores que a do Sol. O efeito detectável dessas reações é o "brilho" das estrelas que se estende por todo o espectro eletromagnético. De fato, há emissão de radiação eletromagnética em todas as

\footnotetext{
${ }^{4}$ No modelo cosmológico conhecido como Big Bang entende-se o "instante inicial" do processo da formação do Universo quando, supostamente, ocorreu uma "grande explosão primordial". Não entraremos em maiores detalhes neste assunto que pode ser estudado

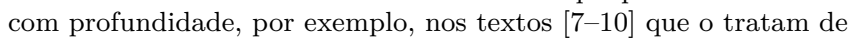
forma abrangente e rigorosa.
} 


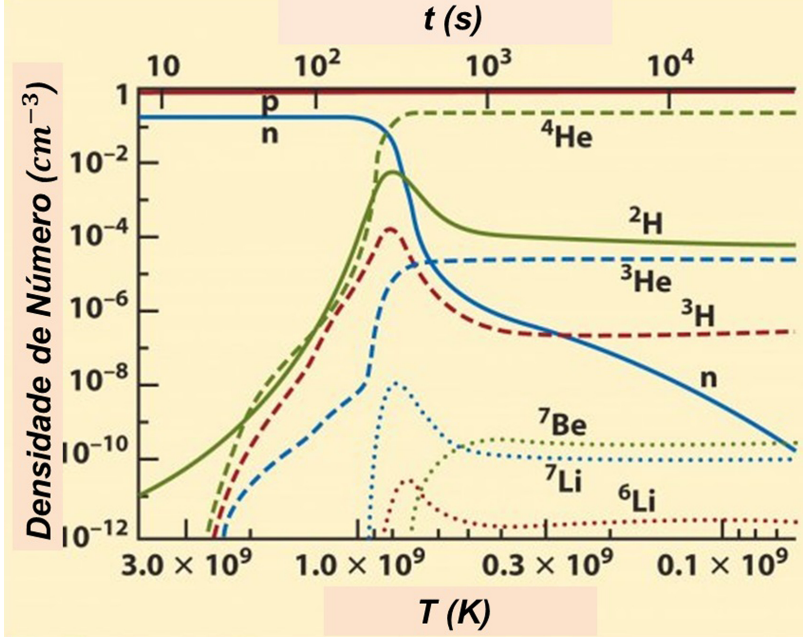

Figura 2: Evolução da abundância relativa dos elementos no processo de nucleossíntese do Universo primordial. Note-se a relação entre a evolução temporal (escala na abcissa superior) e a diminuição da temperatura (escala na abcissa inferior). Diversos nuclídeos apresentam saturação da densidade; veja, por exemplo, a linha tracejada, para o ${ }_{2}^{4} \mathrm{He}$. Figura adaptada, do endereço web http://www . astro.ucla.edu/ wright/BBNS .html

frequências. Um relato pedagógico sobre estrelas, sua evolução e estabilidade foi feito por S. Chandrasekhar [11].

O processo de produção de energia, como consequência da nucleossíntese, nas estrelas jovens se inicia com uma concentração inicial $3: 1$ de hidrogênio para hélio permitindo reações de diferentes tipos. Elas ocorrem em uma sucessão de etapas, como proposto, já em 1939, por H. Bethe $[12$. No processo chamado $p p 1$ tem-se

$$
\left.\begin{array}{ccc}
p+p & \longrightarrow & { }^{2} H+e^{+}+\nu_{e} \\
p+{ }^{2} \mathrm{H} & \longrightarrow & { }^{3} \mathrm{He}+\gamma \\
{ }^{3} \mathrm{He}+{ }^{3} \mathrm{He} & \longrightarrow & { }^{4} \mathrm{He}+p+p
\end{array}\right\}
$$

cujo resultado líquido é a formação de um núcleo de ${ }^{4} \mathrm{He}$ mais partículas leves, raios- $\gamma$ e a liberação de energia, porém com a produção de deutério $\left({ }^{2} \mathrm{H}\right)$ e ${ }^{3} \mathrm{He}$ em etapas intermediárias. Antes que todo o hidrogênio da estrela se converta em hélio, a segunda etapa do processo pode começar desde que haja abundância suficiente de ${ }^{4} \mathrm{He}$ para disparar o seu início. Isto se dá porque a força gravitacional atua de forma a aumentar a probabilidade de colisão entre os núcleos de hélio induzindo novas cadeias de reações, em sequências de reações conhecidas como pp2,

$$
\left.\begin{array}{ccc}
{ }^{3} \mathrm{He}+{ }^{4} \mathrm{He} & \longrightarrow & { }^{7} \mathrm{Be}+\gamma \\
{ }^{7} \mathrm{Be}+e^{-} & \longrightarrow & { }^{7} \mathrm{Li}+\nu_{e} \\
{ }^{7} \mathrm{Li}+\mathrm{p} & \longrightarrow & { }^{4} \mathrm{He}+{ }^{4} \mathrm{He} .
\end{array}\right\}
$$

Após a segunda das reações em (4) pode ocorrer que, em vez de absorver um elétron, o núcleo de ${ }^{7} \mathrm{Be}$ pode capturar um próton para finalmente também decair em duas partículas $\alpha$, com a seguinte sequência

$$
\left.\begin{array}{ccc}
{ }^{7} \mathrm{Be}+p & \longrightarrow & { }^{8} \mathrm{~B}+\gamma \\
{ }^{8} \mathrm{~B} & \longrightarrow & { }^{8} \mathrm{Be}+e^{+}+\nu_{e} \\
{ }^{8} \mathrm{Be} & \longrightarrow & { }^{4} \mathrm{He}+{ }^{4} \mathrm{He} .
\end{array}\right\}
$$

Haverá então a produção de um núcleo de boro- $8\left({ }^{8} B\right)$, que é instável, decaindo para o berílio- $8\left({ }^{8} B e\right)$, que tem um tempo de meia vida bastante curto, $10^{-16} s$, que decai em duas partículas $\alpha$, praticamente sem liberação de energia. Portanto, o resultado líquido é $p+{ }^{7} \mathrm{Be} \longrightarrow$ ${ }^{4} \mathrm{He}+{ }^{4} \mathrm{He}$.

Com a formação de partículas $\alpha$ em quantidade suficiente, inicia-se a cadeia de "queima' $\sqrt{5}$ destas partículas. Entretanto, para isso é necessário que a temperatura da estrela seja maior que $10^{8} K$ por causa da barreira coulombiana mais alta. Isso só pode acontecer em estrelas com massas da ordem de, ou superior a, 2, $5 M_{\odot}$ (onde $M_{\odot}$ simboliza a massa do Sol) por um processo representado pelas reações

$$
\left.\begin{array}{llc}
{ }^{4} \mathrm{He}+{ }^{4} \mathrm{He} & \longrightarrow & { }^{8} \mathrm{Be}+\gamma \\
{ }^{8} \mathrm{Be}+{ }^{4} \mathrm{He} & \longrightarrow & { }^{12} \mathrm{C}+\gamma
\end{array}\right\}
$$

Embora o núcleo de ${ }_{4}^{8} B e$ seja altamente instável, antes de sua fissão há uma probabilidade finita de captura de uma partícula $\alpha$ - em uma reação exotérmica - e, por meio dessa reação, irá se formar o nuclídeo estável ${ }_{6}^{12} C$, processo conhecido como triplo- $\alpha$ ou $3 \alpha$ 13.

Em sequência, havendo núcleos de carbono em quantidade suficiente em estrelas de bastante massa, a captura $\alpha$ torna-se possível, dando início à síntese do ${ }_{8}^{16} O$, que, por sua vez, é usado na síntese do ${ }_{10}^{20} \mathrm{Ne}$,

$$
\left.\begin{array}{llc}
{ }^{12} \mathrm{C}+{ }^{4} \mathrm{He} & \longrightarrow & { }^{16} \mathrm{O}+\gamma \\
{ }^{16} \mathrm{O}+{ }^{4} \mathrm{He} & \longrightarrow & { }^{20} \mathrm{Ne}+\gamma
\end{array}\right\}
$$

Em seguida, uma variedade de processos nucleares se manifesta levando à síntese dos elementos e nuclídeos mais pesados. Por exemplo, as reações carbono-carbono

$$
{ }^{12} \mathrm{C}+{ }^{12} \mathrm{C} \longrightarrow\left\{\begin{array}{l}
{ }^{24} \mathrm{Mg}+\gamma \\
{ }^{23} \mathrm{Na}+\mathrm{p} \\
{ }^{20} \mathrm{Ne}+\alpha,
\end{array}\right.
$$

requerem temperaturas da ordem $5-10 \times 10^{8} \mathrm{~K}$ em estrelas massivas, enquanto que as reações oxigênio-oxigênio requerem temperatura $T>10^{9} \mathrm{~K}$

$$
{ }^{16} \mathrm{O}+{ }^{16} \mathrm{O} \longrightarrow\left\{\begin{array}{ccc}
{ }^{32} S & + & \gamma \\
{ }^{31} \mathrm{P}+ & p \\
{ }^{31} S+ & + \\
{ }^{28} \mathrm{Si}+ & \alpha
\end{array}\right.
$$

Estrelas com massas no intervalo $10-15 M_{\odot}$ conseguirão fundir núcleos gradualmente mais pesados até conseguir

\footnotetext{
${ }^{5}$ Tradução do inglês burning; esta palavra é usada no sentido de combustão via fusão nuclear das partículas $\alpha$ e com consequente liberação de energia.
} 
produzir o elemento ferro, e a estrela poderá ser descrita em termos de camadas concêntricas, um formato análogo ao de uma cebola, onde em cada camada haverá um processo próprio. No centro da estrela, em seu caroço que permanece inerte, se concentram os elementos mais pesados, de silício até o ferro, isto é, não há mais queima, pois é impossível sintetizar elementos mais pesados pela fusão. Também, na camada mais exterior da estrela não há queima do hidrogênio, por falta de pressão suficiente. Em algum momento, quando a estrela consiste essencialmente de ferro, silício e outros elementos vizinhos na tabela periódica, a queima por reações termonucleares para e a seguir pode se iniciar outra fase do processo de evolução, a da contração ou colapso gravitacional. Havendo uma quantidade suficiente de nêutrons livres durante a contração de uma estrela, um elemento mais pesado que o ferro pode ser sintetizado pela captura de um nêutron por um núcleo já existente, em um processo do tipo

$$
{ }_{Z}^{A} X+n \longrightarrow{ }_{Z}^{A+1} X+\gamma \longrightarrow\left\{\begin{array}{l}
{ }_{Z+1}^{A+1} Y+e^{-}+\bar{\nu}_{e} \\
{ }_{Z-1}^{A+1} W+e^{+}+\nu_{e}
\end{array}\right.
$$

Após a captura de um nêutron pelo nuclídeo ${ }_{Z}^{A} X$ haverá um decaimento por emissão $\beta^{+}$ou $\beta^{-}$levando-o a um radionuclídeo ${ }_{Z+1}^{A+1} Y$ ou a um ${ }_{Z-1}^{A+1} W$, que, por sua vez, irá decair sequencialmente até chegar a algum nuclídeo estável, que será um outro elemento. Neste caso, os decaimentos $\beta^{ \pm}$adquirem assim um papel importante na nucleossíntese. Tais processos podem ocorrer na implosão de uma estrela de nêutrons velha (tornando-se uma supernova [14]), assim como na coalescência de um sistema binário de estrelas de nêutrons. Por estrela de nêutrons entende-se uma estrela que é constituída por cerca de $10^{6}$ nêutrons por $\mathrm{cm}^{3}$ para cada outro constituinte, seja ele um próton ou um núcleo. A teoria comumente aceita para explicar a nucleossíntese dos elementos mais pesados que o ferro se fundamenta na existência de dois tipos de processos para a ocorrência das reações 10 e que exigem um grande fluxo de nêutrons: (1) o chamado processo-s (s para slow), que é um processo de "captura lenta" de um nêutron, é responsável pela produção de metade dos elementos além ferro sendo que ele ocorre em estrelas em final de estágio evolucionário, com massa entre 1 e $10 M_{\odot}$; e (2) o processo-r (r para rapid), este processo de "captura rápida" ocorre em estrelas que têm uma densidade neutrônica da ordem de $10^{20} / \mathrm{cm}^{3}$, o que permite uma maior probabilidade de captura; veja mais em 15, 16 e em artigos seminais como, por exemplo, 6, 13, 17, 18. Outro processo de nucleossíntese proposto, denominado processo-rp [19 20], pode ocorrer em estrelas ricas em prótons e em temperaturas maiores que $10^{8} \mathrm{~K}$. Ele consiste na captura rápida de um próton (queima de hidrogênio), descrito pela reação

$$
{ }_{Z}^{A} X+p \longrightarrow{ }_{Z+1}^{A+1} X+\gamma \longrightarrow\left\{\begin{array}{l}
{ }_{Z+2}^{A+1} Y+e^{-}+\bar{\nu}_{e} \\
{ }_{Z}^{A+1} W+e^{+}+\nu_{e}
\end{array}\right.
$$

Neste processo ocorre uma transmutação de um elemento em outro $(Z \rightarrow Z+1)$, de maior número atômico, com a liberação de energia na forma de um raio- $\gamma$.

A seguir, nas seções 3 e 4 iremos descrever a fórmula semiempírica de massa, que descreve as diferentes contribuições para a massa (ou energia) dos nuclídeos, e como, a partir dela, pode-se obter tanto: (1) a linha de estabilidade, que é a linha sobre a qual se situam os nuclídeos estáveis em um gráfico $Z \times A$, assim como das, (2) linhas limítrofes, que são as duas linhas fronteiriças, como podem ser vistas na Figura 3. Sobre estas linhas se situam os nuclídeos radioativos tais que para além de um número de massa $A$ seja praticamente impossível, devido a considerações energéticas, sintetizar um nuclídeo com número de massa $A+1$. Não obstante, os nuclídeos sobre estas linhas podem ser produzidos em laboratório, via colisões propiciadas por aceleradores de partículas, e admissivelmente também em processos astrofísicos.

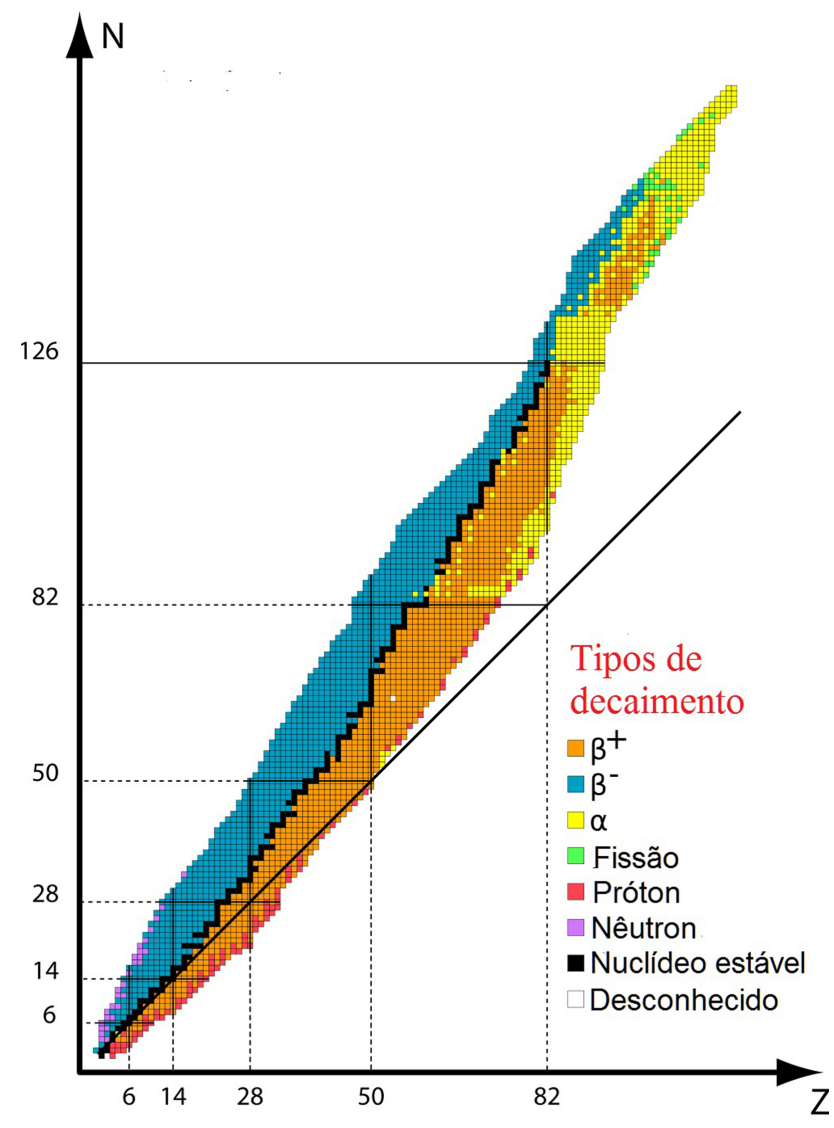

Figura 3: Carta de nuclídeos. A cor dos quadradinhos indica a categoria do nuclídeo, estável ou radioativo, e por qual processo ele decai. A linha sólida a $45^{\circ}$ corresponde a $N=Z$. As linhas de "loci" ligando os quadradinhos mais extremos, os quais correspondem aos maiores valores de $Z$, ou de $N$, para um valor de $A$ fixo, são as chamadas linhas limítrofes. A linha central em zigue-zague liga os nuclídeos estáveis. 


\section{Fórmula semiempírica de massa}

Ao observarmos a carta de todos os nuclídeos existentes na Natureza ou aqueles produzidos em laboratório até o presente [1], é imediato constatar que encontramos um número finito deles - de fato $\sim 3000$, veja a Figura 3 . onde cada quadradinho representa um nuclídeo. Uma primeira conclusão é que os núcleos estão sujeitos a uma tendência de saturação no número de seus constituintes: não encontramos núcleos com número arbitrário de prótons ou nêutrons. Esta limitação pode ser entendida de forma qualitativa diretamente da análise do balanço entre a força nuclear atrativa, forte e de curto alcance, que atua indistintamente entre prótons quanto nêutrons, e a repulsão coulombiana, mais fraca, atuando somente entre os prótons, sendo porém de longo alcance. Nesta perspectiva, os núcleos com $A>50$ tendem a ter mais nêutrons do que prótons, $N>Z$, o que é mais vantajoso do ponto de vista da energia total do núcleo pois ele se torna mais ligado do que um núcleo que tivesse comparativamente menos nêutrons [21]. Contudo, em condições normais, não há núcleos feitos só de prótons ou só de nêutrons.

$\mathrm{Na}$ carta de nuclídeos da Figura 3 observamos que os núcleos mais instáveis estão localizados nas margens extremas tanto à direita quanto à esquerda da linha de estabilidade, ou seja, nas bordas da carta encontram-se os núcleos que têm o menor tempo de meia vida possível, por isso eles não participam ativamente da constituição da matéria mas são muito importantes na produção, por processos de decaimento, de outros núcleos que são estáveis.

Do ponto de vista rigoroso de um tratamento teórico que leve em conta todos os aspectos quânticos do sistema de muitos prótons e nêutrons, as previsões sobre as propriedades gerais destes sistemas nucleares estão limitadas por grandes dificuldades técnicas de cálculos numéricos sofisticados. Na maioria dos casos, as previsões são realizadas para os núcleos estáveis em seus estados fundamentais ou com baixa energia de excitação. Ao longo do tempo, foram desenvolvidos métodos aproximativos que levam em conta as propriedades conhecidas da força nuclear, bem como da força coulombiana, de tal maneira a permitir cálculos visando a descrição das propriedades básicas dos núcleos 22, 23.

Não obstante os resultados bem fundamentados provenientes destes métodos sirvam de base sólida para análises dos sistemas nucleares e estudos sobre a limitação dos nuclídeos que podem existir (ou serem produzidos), considerações baseadas em modelos simples também podem ser de grande valia nesta tarefa. Neste sentido, as analogias entre núcleos e gotas líquidas - já intensamente debatidas desde a década de 1930 - serviram de base para a elaboração do modelo de Bethe-Bacher-Weissäcker, que deu origem à formula semiempírica de massa 24 27. Do ponto de vista histórico, é interessante mencionar que um estudo clássico sobre a estabilidade de gotas eletrifi- cadas de líquido mostrou que elas se quebravam quando a carga elétrica excedia um certo valor e ela era posta a oscilar 28].

As características comuns nos dois casos - gotas e núcleos - se referem a propriedades globais de ambos: a) saturação da densidade de massa e de carga no centro do núcleo; b) as energias totais de ligação dos núcleos crescem aproximadamente de forma linear com o número de núcleons, $A$, ou seja, com o número de massa do núcleo; c) o raio nuclear é proporcional à raiz cúbica do número de massa, ou seja, o volume é proporcional ao número de núcleons.

Por conseguinte, a fórmula semiempírica de massa leva em conta a energia total de um núcleo somando as contribuições separadas devidas às massas de seus constituintes $\left(Z M_{1_{H}}+(A-Z) M_{n},\right)$, ao seu volume $\left(-a_{v} A\right)$, à sua superfície $\left(+a_{\text {sup }} A^{2 / 3}\right)$ e à interação coulombiana dos prótons $\left(+a_{c} Z^{2} A^{-1 / 3}\right)$. Estes termos têm inspiração clássica e são complementados por outros termos de caráter quântico: um termo que leva em conta a energia associada à assimetria entre o número de prótons e o de nêutrons, $\left(+a_{a s s}(A-2 Z)^{2} A^{-1}\right)$ e outro associado à constatação de que núcleos com números pares de prótons e de nêutrons são mais estáveis que nos outros casos $\left(+\eta a_{p} A^{-1 / 2}\right)$. É importante observar que falamos indistintamente de energia e massa praticamente como sinônimos já que usamos aqui a relação $E=m c^{2}$ da relatividade restrita de forma explícita.

A expressão essencial para a massa de um núcleo no modelo de gota líquida é dada então por

$$
\begin{aligned}
& M(A, Z)=Z M_{1_{H}}+(A-Z) M_{n}-a_{v} A+a_{\mathrm{sup}} A^{2 / 3} \\
& +a_{c} \frac{Z^{2}}{A^{1 / 3}}+a_{a s s} \frac{(A-2 Z)^{2}}{A}+\eta a_{p} A^{-1 / 2}
\end{aligned}
$$

As constantes são definidas por ajuste aos valores da carta de nuclídeos de tal forma que a expressão valha para o maior número possível de núcleos; aqui adotamos os valores propostos por A. H. Wapstra em [29], que são: $a_{v}=15,835 \mathrm{MeV}, a_{\text {sup }}=18,33 \mathrm{MeV}, a_{c}=0,72 \mathrm{MeV}$, $a_{a s s}=23,20 \mathrm{MeV}$ e $a_{p}=11,20 \mathrm{MeV} \mathrm{com}$

$$
\eta=\left\{\begin{array}{cl}
-1 & \text { para núcleos com } Z \text { par e } N \text { par } \\
0 & \text { para núcleos com } Z \text { par e } N \\
& \text { ímpar; ou } Z \text { ímpar e } N \text { par } \\
1 & \begin{array}{l}
\text { para núcleos com } Z \text { ímpar e } \\
N \text { ímpar }
\end{array}
\end{array},\right.
$$

embora encontram-se na literatura vastos conjuntos de valores que diferem ligeiramente destes. Por sua vez, as massas do átomo de hidrogênio e do nêutron são $M_{1_{H}}=$ 938, $783 \mathrm{MeV}$ e $M_{n}=939,565 \mathrm{MeV}$ respectivamente.

A importância deste modelo provém em grande parte de sua inerente abrangência descritiva. É reconhecido, porém, que para núcleos leves as estimativas numéricas previstas pela fórmula de massa desviam dos resultados 
medidos. A razão para aqueles desvios é encontrada na própria fundamentação do modelo: a analogia com gotas líquidas não se mantém para núcleos com poucos núcleons. No sentido de aprimorar este modelo de forma a incorporar efeitos quânticos, não presentes na fórmula semiempírica de massa e, paralelamente, adaptá-la para descrever mais apropriadamente núcleos leves - embora mantendo a simplicidade da formulação original -, foram propostas mudanças em sua formulação, como, por exemplo, aquelas que constam nas referências 30 35.

\subsection{Linha de estabilidade}

Mesmo com a fórmula de massa dada por sua expressão mais simples, Eq. (12), já é possível verificar alguns re- sultados sobre a estabilidade dos núcleos. De fato - como é bem conhecido 2427 e aqui apresentado por razão de completeza -, se considerarmos o número de massa $A$ fixo (ou seja, tomando uma linha de isóbaros, que na carta de nuclídeos corresponde, em um gráfico cartesiano $N \times Z$, à reta perpendicular à linha $Z=N$ ) podemos reescrever a Eq. 12 - de forma mais conveniente para melhor extrair o conteúdo da física contida - como um polinômio na variável $Z$

$$
M(A, Z)=C_{1}(A)+C_{2} Z+C_{3}(A) Z^{2}
$$

onde os coeficientes são

$$
\left.\begin{array}{l}
C_{1}(A)=\left(M_{n}-a_{v}+a_{\text {ass }}\right) A+a_{\text {sup }} A^{2 / 3}+\eta a_{p} A^{-1 / 2} \\
C_{2}=M_{1_{H}}-M_{n}-4 a_{a s s} \\
C_{3}(A)=a_{c} A^{-1 / 3}+4 a_{a s s} A^{-1}
\end{array}\right\}
$$

do que observamos uma dependência quadrática em $Z$ na linha de isóbaros. O ponto de mínimo da Eq. (14) é $Z_{0}(A)=-C_{2} /\left(2 C_{3}(A)\right)$ (porém, de fato, deve-se considerar o valor inteiro mais próximo do número decimal $Z_{0}$ ) e deve corresponder ao número atômico do núcleo estável com número de massa $A$. O conjunto formado por todos os números Int $\left\{Z_{0}(A)\right\}$ dá origem, em um gráfico cartesiano $N \times Z$, a uma região conhecida como vale de estabilidade da carta de nuclídeos, veja a Figura 1 onde foram tabelados 254 nuclídeos estáveis conhecidos. Em um gráfico $Z \times A$ o vale é representado mais simplesmente por uma linha, a curva (3) na Figura 4 onde cada cruz representa um nuclídeo e a linha sólida provém do

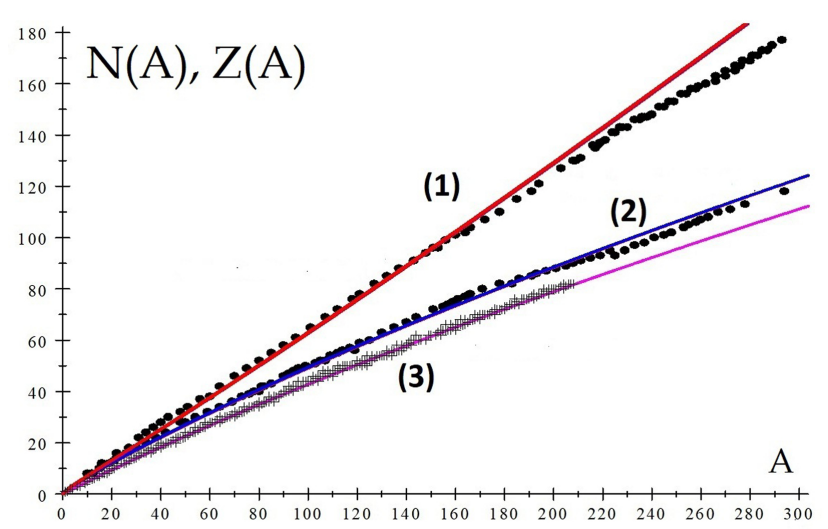

Figura 4: Os círculos cheios correspondem a nuclídeos das regiões limítrofes obtidos da carta da IAEA [1] e as linhas sólidas são os valores calculados a partir da fórmula semiempírica de massa, (1) para os nêutrons e (2) para os prótons. Na curva (3) as cruzes representam os nuclídeos estáveis conhecidos e a linha sólida provém do cálculo a partir da fórmula de massa. cálculo a partir da fórmula de massa. Constata-se que a concordância com os dados empíricos é bastante boa, fato este que dá um respaldo de confiança à fórmula semiempírica. Dependendo do número de núcleons no núcleo, a contribuição do termo de emparelhamento, Eq. (13), se dá de forma diferente. De fato haverá duas parábolas em alguns casos [24].

\section{As linhas limítrofes na carta de nuclídeos}

A junção de conceitos relacionados com a fórmula semiempírica de massa com preceitos da mecânica quântica referentes a relações de incerteza pode estender o escopo de aplicação da abordagem semiclássica daquela fórmula. No que segue, objetivamos mostrar como podemos usar a relação de incerteza energia-tempo em conexão com a fórmula semiempírica de massa para determinar as linhas limítrofes de prótons e nêutrons na carta de nuclídeos. Esta conexão pode ser explorada quantitativamente uma vez compreendido o sentido das quantidades físicas envolvidas naquela relação de incerteza [36]. Discussões mais detalhadas de como este princípio de incerteza é obtido e em que condições ele pode ser aplicado podem ser estudadas, por exemplo, nas referências 37 40.

Aqui usaremos de forma explícita o conceito referente à incerteza de energia como sendo associado a um processo físico determinado: qual a energia associada à transformação de um núcleo com um certo número de massa, em outro com o mesmo número de massa, mas com um próton ou um nêutron a menos, ou seja, ocorrendo apenas uma mudança de uma unidade de carga coulombiana no núcleo. Da mesma forma, o conceito de incerteza no 
tempo será entendido como sendo um intervalo $\Delta t$ associado àquele processo específico. Claro está que para estabelecermos este $\Delta t$ precisamos determinar escalas de tempo típicas dos processos nucleares que queremos analisar. Neste sentido, uma abordagem semiclássica nos guia na determinação de uma expressão para $\Delta t$ que se mostra compatível com os preceitos da mecânica quântica e com a fenomenologia nuclear. A dependência com o número de massa $A$ desta prescrição para $\Delta t$ é um elemento essencial em nossa abordagem teórica do problema em questão.

Como já dito, observamos que, para um dado número de massa $A$, há um núcleo com o maior número possível de prótons e outro com o maior número de nêutrons; o conjunto daqueles nuclídeos, para todos os $A^{\prime} s$, será chamado de linha limítrofe de prótons ou nêutrons, respectivamente. Claro está que aqueles nuclídeos são os mais instáveis que existem e que, para além deles, admitese, não devem existir outros: eles formam o conjunto dos nuclídeos maximamente instáveis que podem ser ainda produzidos artificialmente ou por nucleogênese.

Nosso objetivo aqui constitui-se em usar a fórmula de massa (14) para calcular a diferença de energia do núcleo quando, para um dado $A$ fixo, o número de prótons $Z$ é aumentado de uma unidade por algum processo como, por exemplo, em uma reação do tipo

$$
p+{ }_{Z-1}^{A} X \rightarrow{ }_{Z}^{A+1} Y^{*} \rightarrow n+{ }_{Z}^{A} Y .
$$

Admite-se que a estrutura nuclear intermediária ${ }_{Z}^{A+1} Y^{*}$ deve existir por um período de tempo "muito curto", como será discutido mais adiante. Desta forma, expressamos aquela diferença de massa como $\Delta M(A, Z)=$ $M(A, Z)-M(A, Z-1)$, a qual, em termos dos coeficientes da Eq. (15), é então dada por

$$
\Delta M(A, Z)=C_{2}-C_{3}(A)+2 C_{3}(A) Z,
$$

observando que esta é uma expressão linear em $Z$. Esta expressão consiste no cálculo da diferença de energia ao longo de uma linha de nuclídeos isóbaros, como pode ser apreciado na carta da IAEA [1]. O termo de emparelhamento 13 não contribui devido ao cancelamento de dois termos iguais mas de sinais opostos.

Vamos agora considerar que o aumento de uma unidade de carga coulombiana no núcleo $Z_{-1}^{A} X$ leve a um outro, ${ }_{Z}^{A} Y$, tão instável que ele decaia, por algum processo de desexcitação, por emissão de um núcleon, por exemplo, ou por outros energeticamente permitidos, como aqueles explicitados na Eq. (11). O tempo de vida média deste novo núcleo deve ser extremamente curto de tal forma que podemos considerar o uso da relação de incerteza energia-tempo 37,40 . É importante ressaltar que a escolha da magnitude de $\Delta t$ delimita o número de núcleons nos nuclídeos da linha limítrofe, ou seja, o intervalo de tempo deverá estar associado à instabilidade que impossibilita a existência de nuclídeos além da linhas limítrofes. Com a escolha específica de $\Delta t$ não queremos descrever os processos físicos que ocorrem em nuclídeos mais próximos da linha de estabilidade, mas apenas mostrar que usando uma física baseada em argumentos fundamentais, é possível estabelecer a condição para que nuclídeos além da linha limítrofe não possam existir. Neste sentido, devemos observar que admitimos que a incerteza $\Delta t$ seja da ordem do tempo estimado para que o novo núcleo ${ }_{Z}^{A+1} Y^{*}$ exista antes de decair e que o intervalo de energia do processo é dado pela Eq. (17). Assim escrevemos a relação

$$
\Delta M(A, Z) c^{2} \Delta t \sim \hbar,
$$

onde a teoria quântica se faz presente por meio da constante de Planck. Como já temos a diferença de energia dada pela Eq. (17), devemos elaborar mais o conceito de intervalo de tempo do processo associado à presença de um próton a mais no núcleo como sugerido de forma qualitativa acima. Assim, o passo seguinte consiste em estimar quantitativamente esse intervalo de tempo - da existência de um próton a mais, com $A$ fixo, e o sequente decaimento do núcleo resultante - que seja o menor possível. Para isto vamos considerar inicialmente, como um guia, a estimativa inicial do tempo característico associado à passagem de um próton livre à velocidade da luz no vácuo pelo diâmetro típico de um núcleo. Esta estimativa nos dará um valor mínimo para o intervalo de tempo procurado; em outras palavras, será um limite inferior. Com este fim, recorremos ao modelo de gota líquida que define o raio nuclear como $R=r_{0} A^{1 / 3}$, onde $r_{0}=1,2 \mathrm{fm}$ (1 $\mathrm{fm}=10^{-15} \mathrm{~m}$ ) é um parâmetro ajustado para dar, em média, o raio dos núcleos 24$]$. Com esta primeira avaliação obtemos então $\Delta t=2 \overline{R / c} \sim 10^{-23} \mathrm{~s}$ para um núcleo com $10 \mathrm{fm}$ de diâmetro, já que $r_{0} / c=1,2 / 3 \times 10^{-23} s$. Consequentemente, este resultado fornece a ordem de grandeza do tempo mínimo que um próton, nestas condições, possa existir na região do núcleo.

Como abrandamento da consideração inicial extrema para $\Delta t$ vamos considerar, para o próton incidente, uma velocidade realística, $v<c$, no referencial do centro de massa do sistema que ele constitui juntamente com o núcleo. Assim,

$$
\Delta t(A) \sim \frac{2 r_{0} A^{1 / 3}}{v}=\frac{2 r_{0} A^{1 / 3}}{\beta c}
$$

$(\beta=v / c)$ e, desta forma, vemos que a expressão para $\Delta t(A)$ é dependente do número de núcleons constituintes do núcleo. Por conseguinte,

$$
\begin{aligned}
& \Delta M(A, Z)[M e V] \simeq \frac{\hbar}{\Delta t(A)}=\frac{\hbar c}{2 r_{0} A^{1 / 3}} \beta \\
& =\frac{197,329}{2,4} \beta A^{-1 / 3}
\end{aligned}
$$

que permite então escrever uma equação para $Z$ em função de $A$,

$$
Z(A)=\operatorname{Int}\left[\frac{\hbar}{2 C_{3}(A) c^{2} \Delta t(A)}-\frac{C_{2}-C_{3}(A)}{2 C_{3}(A)}\right]
$$


onde Int significa "tomar o maior inteiro do número

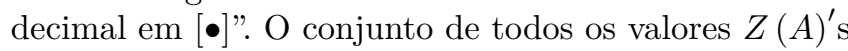
assim calculados para todos os $A$ 's determina a linha limítrofe dos prótons.

Para realizar os cálculos adotamos $\beta=0,7$; este número não foi fixado para obter um melhor ajuste aos dados (como minimização $\chi^{2}$ ), mas foi simplesmente um valor usado como sendo representativo para o intervalo de tempo. Constatamos que valores próximos de $\beta=0,7$ não mudam substancialmente os resultados. O aspecto essencial da proposta para $\Delta t(A)$ é a sua dependência com $A^{1 / 3}$. A linha limítrofe foi calculada usando a Eq. 21 com os parâmetros da fórmula semiempírica de massa e a comparação com os dados da carta de nuclídeos é mostrada na Figura 4 Embora a linha calculada (linha (2) para os prótons) não coincida exatamente com os valores extraídos da carta de nuclídeos da IAEA (círculos pretos), de forma geral, a concordância é satisfatória uma vez que não foi realizado qualquer ajuste de parâmetros. Observa-se também a boa concordância mesmo na região de baixo número de massa, quando a descrição do núcleo como uma gota líquida costuma ser falha.

Para valores de $A$ onde não há acordo entre a linha calculada e os dados experimentais, as limitações da fórmula de massa, como suporte único para descrever a existência de todos os nuclídeos nas linhas limítrofes, ficam manifestas. Podemos creditar parte dos desvios como provenientes de efeitos quânticos não levados em conta no modelo simples que busca apenas uma descrição semiquantitativa. Certamente, uma melhor descrição necessitaria de cálculos usando modelos baseados no tratamento formal de muitos corpos 22, 23, cuja exigência de recursos computacionais, em termos de tempo e memória, seriam bastante extensos, e esta discussão foge do escopo da presente proposta.

Da mesma forma pode-se proceder com os cálculos para a linha limítrofe dos nêutrons. Calcula-se a diferença de energia

$$
\Delta M(A, Z)=M(A, N)-M(A, N-1)
$$

e usa-se, de novo, o princípio de incerteza energia-tempo para se obter uma equação para o número de nêutrons do núcleo que estará na linha limítrofe para um dado valor de $A$,

$$
\begin{aligned}
& N(A)=\operatorname{Int}\left\{\frac { 1 } { D _ { 3 } ( A ) } \left[-D_{1}(A)-D_{2}(A)\right.\right. \\
& \left.\left.+\frac{\hbar}{\Delta t(A)}+\left(M_{n}-M_{1_{H}}\right)\right]\right\}
\end{aligned}
$$

onde

$$
\left.\begin{array}{l}
D_{1}(A)=-4 a_{a s s}+a_{c} A^{-1 / 3} \\
D_{2}(A)=-4 a_{a s s} A^{-1}-2 a_{c} A^{2 / 3} \\
D_{3}(A)=2 a_{c} A^{-1 / 3}+8 a_{a s s} A^{-1}
\end{array}\right\} .
$$

O conjunto de todos os valores de $N$ para os $A$ 's da carta de nuclídeos dará a linha limítrofe dos nêutrons. Esta linha também está representada na Figura 4, linha (1), juntamente com os correspondentes números de nêutrons extraídos da carta de nuclídeos. Aqui foram usados os mesmos parâmetros da fórmula semiempírica de massa e $\beta=0,7$. Também neste caso o acordo é bastante bom até nuclídeos de número de massa $A \approx 180$, porém aparecendo uma discordância significativa apenas para valores de $A$ acima daquele. Neste caso, o desacordo pode também ser entendido como originário da inadequação do modelo em descrever sistemas nucleares onde os efeitos quânticos de muitos corpos 22, 23] se manifestam de forma a competir com aqueles semiclássicos.

Como última observação, a conjectura sobre o raio nuclear pode ser alvo de considerações fenomenológicas adicionais que visam refinar seu valor em função do número de prótons e nêutrons, levando em conta a diferença $|N-Z|$. Estas correções descrevem mudanças no raio nuclear devidas a excessos de prótons ou nêutrons que, em princípio, dão origem a halos de núcleons fora de uma parte central ocupada por um número igual de prótons e nêutrons. Uma forma proposta que dá o raio nuclear nestas condições é $R(A)=r_{0}(1-b(N-Z) / A) A^{1 / 3}$, com $r_{0}=1,269 \mathrm{fm}$ e $b=0,252$ [41]. Estes valores são provenientes de ajustes em um grande número de dados e produzem um bom acordo com os valores experimentais. Os cálculos para a linha limítrofe dos prótons, por exemplo, foram por nós realizados com o novo valor para $r_{0}$ e adicionalmente com o parâmetro $b$, sendo mantido $\beta=0,7$. $\mathrm{O}$ resultado foi comparado com aquele obtido anteriormente e notamos que não há qualquer mudança sensível nos novos resultados, praticamente coincidindo com aqueles calculados com a expressão simples $R(A)=1,2 A^{1 / 3}$. Este fato corrobora nossa percepção de que a dependência com $A^{1 / 3}$ é o elemento essencial na descrição do raio nuclear, e não os detalhes finos dos parâmetros a ela associados. Em outras palavras, no cálculo do intervalo de tempo associado à relação de incerteza o efeito global dominante é a dependência com $A^{1 / 3}$ no raio. Este, por sua vez, estabelece uma escala de tamanho dentro do qual o processo nuclear ocorre.

\section{Conclusões}

Mostramos aqui como obter uma estimativa para as linhas limítrofes na carta de nuclídeos - as fronteiras dos constituintes da matéria - a partir de considerações básicas de física nuclear e de mecânica quântica. De fato, a abordagem apresentada é uma extensão da ideia aventada no livro texto dos autores [24] e não levada a uma aplicação mais ampla, o que foi feito aqui. Essa forma de obtenção daquelas linhas ilustra a utilidade da relação de incerteza energia-tempo $37-40$. Fizemos uma aplicação direta desta relação no caso particular da determinação de uma estimativa das linhas limítrofes para a existência - durante um tempo suficiente para terem suas propriedades medidas - de núcleos atômicos. Esta consideração sobre a relação de incerteza é feita nas 
condições em que o núcleo é altamente instável, o que de fato ocorre para núcleos com grande excesso de prótons sobre nêutrons e vice versa.

Os elementos essenciais da presente abordagem são: (a) a diferença de energia associada ao processo pelo qual o número de prótons/nêutrons é aumentado de um, mantendo $A$ fixo, e (b) o intervalo de tempo que este núcleo se mantém nesta situação. A implementação desses dois elementos é feita usando: (1) a fórmula semiempírica de massa, a qual permite calcular a diferença de energia, enquanto (2) a ordem de grandeza do intervalo de tempo para o processo nuclear ocorrer é estimada por meio do cálculo da razão do diâmetro do núcleo e da velocidade com que um núcleon incidindo sobre ele permaneceria na região de sua extensão espacial. Com as considerações do item (2) pode-se ter um guia para a escala de tempo do processo que se quer descrever.

Vimos portanto que um cálculo simples, porém baseado em argumentos sólidos de física nuclear, fornece uma descrição bem consistente com aquilo que é medido experimentalmente, de acordo com os dados da carta de nuclídeos, e ressaltamos que não houve um "ajuste de parâmetros" para a obtenção das linhas limítrofes. Acreditamos que os desvios observados são devidos à inadequação do modelo simples de gota líquida nuclear para descrever sistemas nucleares complexos como o núcleo atômico com $A>180$. Não obstante, a constatação de que um tratamento sem sofisticações de cálculo permite obter um padrão descritivo para mais de uma centena de nuclídeos que constituem as linhas limítrofes dos constituintes da matéria é um indicador de que há, no mínimo, uma boa base qualitativa na presente proposta.

\section{Agradecimentos}

SSM agradece ao Conselho Nacional de Desenvolvimento Científico e Tecnológico, $\mathrm{CNPq}$, pelo apoio financeiro concedido por meio de uma bolsa de pesquisa. Os autores também agradecem o Dr. Marcelo A. Marchiolli por críticas e valiosas sugestões.

\section{Referências}

[1] https://www-nds.iaea.org/relnsd/vcharthtml/ VChartHTML.html

[2] https://www.timeshighereducation.com/news/ perutz-rubbishes-popper-and-kuhn/154140. article

[3] C. Weiner, Phys. Today 25, 40 (1972).

[4] G. Karp, Cell and Molecular Biology, Concepts and Experiments (John Wiley \& Sons, Hoboken, 2010).

[5] G. Marx, Phys. Educ. 36, 375 (2001).

[6] K.M. Burbridge, G.R. Burbridge, W.A. Fowler e F. Hoyle, Rev. Mod. Phys. 29, 547 (1957).

[7] C.E. Rolfs e W.S. Rodney, Cauldrons in the Cosmos (The University Press of Chicago, Chicago, 1988).

[8] E.W. Kolb e M.S. Turner, The Early Universe (Addison Wesley Publ. Co., Redwood City, 1990).
[9] J.L. Basdevant, J. Rich e M. Spiro Fundamentals in Nuclear Physics: From Nuclear Structure to Cosmology (Springer Science+Business Media, New York, 2005).

[10] C. Iliadis, Nuclear Physics of Stars (Wiley-VHC Verlag, Weinheim, 2015).

[11] S. Chandrasekhar, Science 226, 497 (1984).

[12] H. Bethe, Phys. Rev. 55, 434 (1939).

[13] F. Hoyle, Astrophysical Journal Supplement 1, 121 (1954).

[14] H.A. Bethe e G. Brown, Scientific American 25 60, 1985.

[15] J. Cowan e F.K. Thielemann, Phys. Today 57 47, 2004.

[16] A. Frebel e T.C. Beers, Phys. Today 71 30, 2018.

[17] P.A. Seeger, I.W.A. Fowler e D.D. Clayton, Astrophysical Journal Supplement 11, 121 (1965).

[18] G. Wallerstein, P. Parker, G.M. Hale, A.E. Champagne, C.A. Barnes, F. Käppeler, V.V. Smith, R.D. Hoffman, F.X. Timmes, C. Sneden et al., Rev. Mod. Phys. 69, 995 (1997)

[19] R.K. Wallace e S.E. Woosley, The Astrophysical Journal Suppl. Series 45, 389 (1981).

[20] H. Schatz, A. Aprahamian, V. Barnard, L. Bildsten, A. Cumming, M. Ouellette, T. Rauscher, F.K. Thielemann e M. Wiescher, Phys. Rev. Lett. 86, 3471 (2001).

[21] E.C. Simpson e M. Shelley, Phys. Educ. 52, 064002 (2017).

[22] P. Ring e P. Schuck, The Nuclear Many-Body Problem (Springer Verlag, Heidelberg, 1980).

[23] D.J. Rowe e J.L. Wood, Fundamentals of Nuclear Models, (World Scientific, Singapore, 2010).

[24] S.S. Mizrahi e D. Galetti, Física Nuclear e de Partículas: Uma introdução (Editora Livraria da Física, São Paulo, 2016).

[25] H. Schechter e C.A. Bertulani, Introdução à Física Nuclear (Editora da Universidade Federal do Rio de Janeiro, Rio de Janeiro, 2007).

[26] E.F. Pessoa, F.A.B. Coutinho e O. Sala, Introdução à Física Nuclear (Editora da Universidade de São Paulo e Editora McGraw-Hill do Brasil, São Paulo, 1978).

[27] S.S.M. Wong, Introductory Nuclear Physics (Prentice Hall, New Jersey, 1990).

[28] J.W.S. Rayleigh, The Theory of Sound, (Dover Publ., New York, 1945) v. 2.

[29] A.H. Wapstra, Handbuch der Physik 38, 31 (1958).

[30] W.D. Myers e W.J. Swiatecki, Nucl. Phys. 81, 1 (1966).

[31] P. Möller, J.R. Nix e K.L. Kratz, Nucl. Data Tabl. 66, 131 (1997).

[32] S. Samanta e S. Adhikari, Phys. Rev. C65, 037301-1 (2002).

[33] D.N. Basu, arXiv:nucl-th/0306061v2 (2004).

[34] C. Lahiri e G. Gangopadhyay, arXiv:nuclth/1110.6093v127 (2011).

[35] G. Gangopadhyay, Int. J. Mod. Phys. E20, 179 (2011).

[36] W. Pauli, General Principles of Quantum Mechanics (Springer-Verlag, Berlin, Heidelberg, 1980).

[37] A.F.R. Piza, Mecânica Quântica (Editora da Universidade de São Paulo, São Paulo, 2002).

[38] A. Messiah, Quantum Mechanics (North Holland Publ., Amsterdam, 1958) v. 1.

[39] D.J. Griffiths, Introduction to Quantum Mechanics (Prentice Hall, New Jersey, 1995).

[40] C. Cohen-Tannoudji, B. Diu e F. Laloë, Quantum Mechanics (John Wiley \& Sons, New York, 1977), v. 1. 
[41] T. Bayram, S. Akkoyun, S.O. Kara e A. Sinan, Acta Physica Polonica 44, 1971 (2013). 